\title{
Ethical Implications of the Perception and Practice of Female Genital Mutilation/Cutting among Women Attending the Antenatal Clinic at a Tertiary Health Facility in Zaria, North-West Nigeria
}

\author{
Usman Nafisat Ohunene ${ }^{1}$, Grace Bola ${ }^{2}$, Nmadu Awawu Grace ${ }^{1}$, Omole Victoria \\ Nanben $^{1}$, Kene-Ibeagha Nneka Christiana ${ }^{3}$ \\ ${ }^{1}$ Department of Community Medicine, College of Medicine, Kaduna State University, Kaduna, Nigeria. \\ ${ }^{2}$ Institute for Women's Health, Faculty of Population Health Sciences, University College London, Huntley \\ Street, London UK. \\ ${ }^{3}$ Department of Community Medicine, Nile University of Nigeria, FCT, Nigeria. \\ Corresponding Author: Usman, Nafisat Ohunene \\ E-mail address: nenezego@gmail.com
}

\begin{abstract}
Background: Female genital mutilation and cutting (FGMC), is recognized internationally as a violation of the basic rights of women and girls. The act is a form of violence since it is most often perpetuated without the victim's consent or awareness of the possible health implications. Nigeria is one of 30 countries worldwide where this practice is still carried out and accounts for $25 \%$ of the circumcised women worldwide. This practice is deeply entrenched in socio-cultural practice in all geo-political zones in Nigeria and is widespread among the poorly educated and people of low socioeconomic status.

Methodology: This was a descriptive cross-sectional study aimed at determining the ethical implications of the perception and practice of FGMC among women attending antenatal at a tertiary hospital in northwest Nigeria. The study participants were selected using systematic sampling. Information was obtained from 237 respondents using semi-structured questionnaires. Results: The results showed that $22.6 \%$ of the respondents believed that FGMC promotes fidelity while $30.3 \%$ believed that it could ease the process of childbirth. About a third of the respondents had experienced FGMC. There was a statistically significant association found between the educational status of the respondents and desire to circumcise their female children $(p<0.0001)$.

Conclusion: This study shows that the about a quarter of the respondents still perceive FGMC to have some benefits. It also revealed that the practice is still prevalent and some respondents intend to carry out FGMC on their non-consenting female children. These perceptions about FGM show that government at all levels need to mount educational programs aimed at eradicating this practice. Empowering women in this region with education will go a long way to ensuring that FGMC is stopped.
\end{abstract}

Keywords: Female genital mutilation, Female genital cutting, basic rights violation, Nigeria

\section{INTRODUCTION}

Female genital mutilation and/or cutting (FGMC) comprises all procedures that involve partial or total removal of the external female genitalia, or other injuries to the female genital organs for non- 
medical reasons. It involves removing and damaging healthy and normal female genital tissue and interferes with the normal functioning of a female's body [1]. The World Health Organization has classified the form of cutting into four categories, based on the severity: Type I (clitoridectomy: removal of the prepuce and part or the entire clitoris); Type II (excision: partial or total removal of the clitoris and the labia minora with or without the labia majora); Type III (infibulation: narrowing of the vaginal introitus achieved by cutting the labia minora and/or the labia majora and apposing the stumps, with or without clitoridectomy); and Type IV (pricking, piercing, incision, stretching, scraping or cauterising of any part of the external female genitalia) [2]. Types I-III are carried out to prevent promiscuity, preserve virginity, and to increase the sexual pleasure of men among others.

The term 'Female Genital Mutilation', (FGM) formally adopted by the United Nations (UN) highlights the gravity of the harm caused by female genital cutting (FGC) practices. FGM terminology discloses the practice of FGC as an extreme human rights violation. This term is however often perceived as inflammatory, judgemental and stigmatising, particularly for women previously exposed to the practice who do not view their bodies, or the bodies of their daughters, as mutilated. The implication within this terminology is that FGM is practised as an act of intentional violence against female children, adolescents and women instead of a valued traditional practice with many perceived benefits. Female Genital Cutting (FGC) has been identified as more neutral, ethically sensitive term [3].

The practice of FGMC is a gross violation of human rights especially considering the fact that in most cases; it is carried out on minors who cannot consent to this harmful act. It is a manifestation of gender inequality that is deeply entrenched in social, economic and political structures in the countries where it is practised [4]. It is seen as an extreme form of discrimination against girls and women [5]. It violates the right to health, sexual and physical integrity; freedom from discrimination; and freedom from torture, cruel, inhuman and degrading treatment [6]. Based on analysis of international health data it's been shown that there is a close link between women's ability to exercise control over their lives and their belief that female genital mutilation should be ended. FGMC is a social convention governed by rewards and punishments such as condemnation, harassment, and ostracism. The practice continues because the perceived social benefits are deemed more important than the potential harm [4].

Globally, over 200 million girls and women have undergone female genital mutilation; with an additional 3 million girls at risk of undergoing this procedure yearly [2]. Majority of the cases of FGMC are however concentrated in only about 30 countries most which are located in Africa. FGMC is widely practised in Africa's most populous nation, Nigeria where about $25 \%$ of the global burden is located. There are regional disparities regarding the burden of the problem, with the highest prevalence in the south-south (77\%), followed by the south-east (68\%) and south-west $(65 \%)$, but practised on a smaller scale in the north, where it paradoxically tends to the more extreme form [7]. The commonest types of FGMC practised in the north are the 'Gishiri cut' which is a form of Type 4 and the Angurya cuts (scraping of tissue surrounding the vaginal orifice) [8]. "Gishiri" cut is usually performed to 'cure' infertility, genital prolapse and to ease difficult childbirth. Gishiri incision accounts for up to $18 \%$ of the urinary fistulae seen in this region [9]. The ability of women to make decisions that affect their personal circumstances (e.g. health) is an essential aspect of their empowerment. However, in North-West Nigeria, only $16.2 \%$ of women in the reproductive age group make decisions concerning their own health [10].

There are few studies focusing on the perception and practice of, and intent to practice FGMC in Kaduna State. There are hardly any studies on the ethical implications of these perceptions and practices in the country. Studies like this give a baseline from which progress towards elimination of the harmful practice can be ascertained. This study aimed at exploring the ethical implications of the perception and practice of FGMC among women attending the ante-natal clinic at a tertiary hospital in north-west Nigeria. 


\section{METHODOLOGY}

The study was conducted at a tertiary hospital, Ahmadu Bello University Teaching Hospital (ABUTH) in Shika, Giwa Local Government area of Kaduna state in March 2016. Giwa has a population of 292,384 according to the 2006 Nigerian census. The people are mainly Hausa, Fulani, Ibo and Yoruba. ABUTH was designed to be the principal health facility for the defunct Northern region. The obstetrics and gynecology department offer its specialist care to patients. The ante-natal clinic (ANC) was the focal point of this study. The clinic runs on a daily basis seeing about 836 women monthly and 10,034 women yearly.

All women attending the ANC of ABUTH were eligible for the study. It was a descriptive crosssectional survey carried out to assess the perception and practice of FGMC. The sample size was calculated using the formula for cross-sectional studies with the proportion from a previous survey set at $25 \%$ [10]. The minimum sample size calculated was 237 . Systematic random sampling was used to select the respondents for the study. Data was collected from the respondents using pretested, interviewer-administered questionnaires. The questionnaire collected data on the sociodemographic characteristics of the respondents, perception and practice of FGMC.

Data was analysed electronically using the Statistical Package for Social Sciences (SPSS) Version 20. Fisher's exact test was used to test for association between variables. Findings were summarised in appropriate tables. Ethical approval was sought and obtained from the Ethics and Scientific Committee of Ahmadu Bello University Teaching Hospital, Shika. Permission was obtained from the Head of the Obstetrics and Gynecology Department. Information about the study was provided to each participant. Their anonymity, the confidentiality of their responses, voluntary participation and the right to withdraw at any stage was emphasized, following which a written consent was obtained from them.

\section{RESULTS}

The response rate from the study was $100 \%$. The greatest proportion (32.1\%) of the respondents were within the age group 20-24 years with the least proportion $(0.8 \%)$ being within $45-49$ years. There were 14 respondents (5.9\%) within the 15-19 years age group. Majority of the respondents were Hausa (52.7\%) and practised Islam (75.5\%). Only 5.9\% of the respondents had no formal education; $38.8 \%$ of them had tertiary education as the highest level of education attained with 22.4 having attained only primary education. Most of the respondents were married $89.5 \%$ (Table 1). Of the respondents interviewed, $98.7 \%$ of them were aware of FGMC. Over a third (31.6\%) of the respondents were felt FGMC was culturally acceptable and $24.4 \%$ of them felt that it involved removing the clitoris because it was a male part of the genitalia. Less than a third (22\%) of the respondents feel that FGMC promotes faithfulness among women. Only 5.6\% of the respondents felt that it would cure infertility. A majority (92.3\%) of the respondents did not feel that FGMC makes a woman complete. Of the respondents interviewed $44 \%$ believed that FGMC could lead to genital infections; $41.9 \%$ of the believed it would lead to excessive bleeding but only $19.2 \%$ of them felt it would cause infertility. The perceptions of respondents are depicted in Table 2.

The prevalence of FGMC among respondents in the study was $32.1 \%$ and about a quarter $(26.9 \%)$ of the study respondents still intended to continue the practice in their families. There was a statistically significant association found between the level of education attained by the respondents and the desire to continue the practice on their female children $(p<0.0001)$. Results show that the higher the level of education, the greater the proportion of respondents' support for discontinuation of the practice of FGMC. However, there was no association found between the desire to continue the practice of FGMC with ethnic group $(p=0.072)$ or religion $(p=0.887)$. 
Table 1: Socio-demographic Characteristics of Respondents $(n=237)$

\begin{tabular}{|l|l|l|}
\hline Variables & Frequency & Percentage \\
\hline Age & & \\
\hline 15-19 years & 14 & 5.9 \\
\hline $20-24$ years & 76 & 32.1 \\
\hline $25-29$ years & 74 & 31.2 \\
\hline $30-34$ years & 43 & 18.2 \\
\hline $35-39$ years & 22 & 9.3 \\
\hline $40-44$ years & 6 & 2.5 \\
\hline $45-49$ years & 2 & 0.8 \\
\hline Ethnic Group & & \\
\hline Hausa & 125 & 52.7 \\
\hline Fulani & 42 & 17.7 \\
\hline Ibo & 28 & 11.8 \\
\hline Yoruba & 31 & 13.1 \\
\hline Others & 11 & 4.6 \\
\hline Religion & & \\
\hline Islam & 179 & 75.5 \\
\hline Christianity & 58 & 24.5 \\
\hline Educational Level & & \\
\hline No formal education & 14 & 5.9 \\
\hline Primary & 53 & 22.4 \\
\hline Secondary & 78 & 32.9 \\
\hline Tertiary & 92 & 38.8 \\
\hline Marital Status & & \\
\hline Single & 25 & 10.5 \\
\hline Married & 212 & 89.5 \\
\hline & & \\
\hline
\end{tabular}

Table 2: Perception of Respondents about FGMC (n=234)

\begin{tabular}{|l|l|l|}
\hline Variables & $\begin{array}{l}\text { Yes } \\
\text { Frequency (\%) }\end{array}$ & $\begin{array}{l}\text { No } \\
\text { Frequency (\%) }\end{array}$ \\
\hline Perceived Benefits of FGMC & & \\
\hline $\begin{array}{l}\text { The clitoris should be removed because it is the male part of } \\
\text { the female body }\end{array}$ & $57(24.4)$ & $177(75.6)$ \\
\hline FGMC promotes a woman's faithfulness to her husband & $66(28.2)$ & $168(71.8)$ \\
\hline FGMC promotes cleanliness & $46(19.7)$ & $188(80.3)$ \\
\hline FGMC makes a woman complete & $18(7.7)$ & $216(92.3)$ \\
\hline Uncircumcised females will become sexually promiscuous & $53(22.6)$ & $181(77.4)$ \\
\hline FGMC is needed to ease childbirth & $71(30.3)$ & $163(69.7)$ \\
\hline FGMC can cure infertility & $13(5.6)$ & $221(94.4)$ \\
\hline FGMC is culturally acceptable & $74931.6)$ & $160(68.4)$ \\
\hline Perceived Harmful Effects FGMC & & \\
\hline Dyspareunia & $64(27.4)$ & $170(72.6)$ \\
\hline Excessive bleeding & $98(41.9)$ & $136(58.1)$ \\
\hline Incontinence & $45(19.2)$ & $189(80.8)$ \\
\hline Infertility & $63(26.9)$ & $171(73.1)$ \\
\hline Genital Infections & $103(44.0)$ & $131(56.0)$ \\
\hline
\end{tabular}




\section{DISCUSSION}

It was observed in the study that majority of the respondents in this study were within the age range of 20-29 years with $5.9 \%$ of them being within the ages of 15 to 19 years. The study also showed that median age at first marriage of respondents was 17.2 years. A study carried out in Kano state, north-west Nigeria similarly showed that majority of the respondents were within the younger age group and were married at a very young age [11]. This picture is not surprising considering the fact that early marriage, as FGM is also a prevalent practice in the northern part of the country where it is rooted in ethnic values and religious beliefs. The median age for first marriage for females in the North-western region of Nigeria where this study was carried out has been reported to be 15.3 years [10]. Early marriage is widely prevalent in Nigeria as a whole, $43 \%$ of girls are reported to be married off before their 18th birthday; $17 \%$ are married before they turn 15. The prevalence of child marriage varies widely from one region to another, with figures as high as $76 \%$ in the North West region [12]. Early marriage is a violation of human rights as the girls' consent is not sought when deciding on her future partner. This practice continues regardless of the well documented physical and mental health problems associated with it [13]. Child marriage is defined as any marriage or union between two people in which one or both parties are younger than 18 years [14]. Child marriage and FGMC both harmful practices and human right violations. They are rooted in issues of gender inequality and are usually the offshoots of norms and traditions where families and communities believe they are protecting girls from social and economic risks. Furthermore, most of the girls are poorly educated; they lack opportunities and skills for income generating activities, and above all lack adequate knowledge of reproductive health. They are further saddled with premature parental responsibility [15].

Majority of the respondents in this study were aware of FGMC. Studies have shown that this practice continues to be prevalent in several parts of Nigeria as well as other African countries so mass awareness of the practice is to be expected [16-17]. Almost a quarter of the respondents believed that FGMC was beneficial because it removed the male part of the genitalia. A study in Lagos, South-western Nigeria showed that $27.4 \%$ of the respondents also believed that FGMC involved cutting off the male part of the genitalia [18]. A third of the respondents in this current study believed that FGMC eased the process of childbirth. Other studies have also shown that some women believe that FGMC (Gishiri cuts) eases childbirth [19-21]. It has been widely documented that a great proportion of women in Nigeria deliver at home [8] and as such, they are attended to by traditional birth attendants (TBA) [10] who carry out Gishiri cuts to aid in the childbirth process [22]. Instruments used are usually unsterilized and these TBA do not have formal training to equip them to perform this procedure [22]. This could result in excessive bleeding, infections among other possible complications [23].

Of the respondents interviewed, 22\% believed that FGMC will promote fidelity among married women and that uncircumcised women were likely to be promiscuous. Studies have shown that this is a common belief among proponents of this practice $[8,18,24]$. FGMC is mainly centred on the need to decrease a woman's sexual desire. This is true within many patriarchal societies where the tradition of FGC is intended to ensure control of female sexuality, chastity and the honour of the community. Sexual health is a basic human right which females in the Northern region especially in the rural areas are being denied based on cultural norms which take away their decision autonomy in sexual matters and place higher importance on the sexual needs of their male counterparts. The key benefit being the fact that it supposedly increases the sexual enjoyment of the males [25]. This practice imbues psychosocial benefits of social acceptance and marriageability and preserving virginity while instilling pride, honour, value, and aesthetics [26]. Some respondents noted that FGMC was important because it was part of their tradition or culture. Performing FGMC was therefore reportedly done out of respect for culture and traditions. This corroborates findings obtained from previous studies where tradition and culture were commonly cited as reasons for perpetuating the practice of FGMC [8-9, 16, 19]. The cultural/traditional values associated with the practice differ from one society to the next, however; it is clear that FGC practices are often viewed as a social good, essential in the 
socialisation of girls [3]. The fact that this practice is deeply embedded in cultural norms makes the abolishment extremely difficult especially because of the perceived social benefits.

A greater proportion of the respondents perceived the practice to be harmful with complications such as dyspareunia, excessive bleeding and genital infections among others. Similarly, a study carried out in Ibadan, South-western Nigeria highlighted these complications as the perceived harm that the practice could inflict on the victim [24]. The fact that a greater proportion of the respondents perceive FGMC to be a harmful practice is encouraging. This is because if it is viewed negatively, they will less likely be inclined to continue the practice especially in situations where they are the decision makers or part of the decision-making team [25].

About a third of the respondents had experienced FGMC in one form or another. Other studies have shown that the practice is still prevalent with rates being as high as $63 \%$ in some areas [24] with others being similar (31.1\%) to the proportions obtained in this study [16]. This underpins the fact that even with the widespread advocacy to end this practice, it hasn't been fully abolished even though prevalence rates are on the decline in some parts of the country. Future generations will be exposed to this act if more concrete measures are not taken to ensure it is stopped. About a quarter of the survey participants still intend to continue the practice with their female children. This is similar to findings in another study in north-west Nigeria where $21.5 \%$ would subject their daughters to FGMC [8]. There was a statistically significant association found between the highest level of education obtained by the respondents in the current study and their desire to continue the practice. The mothers with the highest level of education did not desire to continue the practice of FGM. This finding was similar to a previous study which showed the same relationship between educational level and desire to continue the practice [8]. The educational level of the mother could be a proxy for female autonomy. The more educated is the more likely she is to contribute to decision making in the household as well as decisions on issues relating to her children and the less likely she will be to favour the propagation of FGMC [27-29].

\section{CONCLUSION}

This study showed that the respondents still believe there are benefits to FGMC, about a third of them had experienced FGMC and about a quarter of them intended to continue the cultural tradition. A culturally competent, gender and ethically sensitive approach is essential to ensure that this practice is abolished in its entirety. Awareness should be raised on the possible dangers of the practice. It is essential to improve female education and carry out capacity building programs for females with vocational training as this will improve their decision-making capabilities. Finally, the practice should be criminalised with heavy penalties meted out to offenders.

\section{REFERENCES}

1. WHO. Female genital mutilation. World Health Organisation Fact sheets. 2018. http://www.who.int/news-room/fact-sheets/detail/female-genital-mutilation. Accessed 30 July 2018.

2. WHO. WHO I Female genital mutilation (FGM). WHO. 2016. http://www.who.int/reproductivehealth/topics/fgm/prevalence/en/. Accessed 12 May 2018.

3. Vissandjée B, Denetto S, Migliardi P, Proctor J. Female genital cutting (FGC) and the ethics of care: community engagement and cultural sensitivity at the interface of migration experiences. BMC Int Health Hum Rights 2014;14(1):13.

4. OHCHR, UNAIDS, UNDP, UNECA, UNESCO, UNFPA, UNHCR, UNICEF, UNIFEM W. Eliminating Female genital mutilation An interagency statement. Geneva WHO. 2008;48.

5. WHO. WHO I Eliminating Female Genital Mutilation. WHO. 2016. http://www.who.int/reproductivehealth/topics/fgm/about/en/. Accessed 5 May 2018.

6. Fisaha K. Female Genital Mutilation: A Violation of Human Rights. J Polit Sci Public Aff 2016;4(2):1-6.

7. Okeke T, Anyaehie U, Ezenyeaku C. An overview of female genital mutilation in Nigeria. Ann Med Health Sci Res 2012;2(1):70-3.

8. Ashimi AO, Amole TG. Perception and attitude of pregnant women in a rural community northwest Nigeria to female genital mutilation. Arch Gynecol Obstet 2015;291(3):695-700. 
9. Ashimi AO, Amole TG, Iliyasu Z. Prevalence and predictors of female genital mutilation among infants in a semi urban community in northern Nigeria. Sex Reprod Healthc 2015;6(4):243-8.

10. NDHS. Nigeria Demographic and Health Survey 2013. Niger Demogr Heal Surv 2013 Natl Popul Comm Fed Repub Niger 2014;1-400.

11. Ashimi AO, Amole TG. Perception and attitude of pregnant women in a rural community northwest Nigeria to female genital mutilation. Arch Gynecol Obstet 2015;291(3):695-700.

12. UNFPA. Marrying too young: end child marriage. 2012. United Nations Population Fund https://www.unfpa.org/end-child-marriage. Accessed 5 November 2018.

13. Daniel MI. Early Marriage of young and adolescent girls: causes and impact on children and society. 2016 https://wyf.org.my/wp-content/uploads/2016/06/Paper-Presentation-1-EarlyMarriage-of-Young-and-Adolescent-Girls.pdf. Accessed 5 November 2018.

14. Malhotra A, Warner A, Mcgonagle A, Lee-Rife S. WHAT THE EVIDENCE SHOWS Solutions to End Child Marriage Solutions to End Child Marriage. 2011 www.icrw.org/childmarriage. Accessed 19 November 2018.

15. Sharma A. Child Marriage among Female Adolescents in Nigeria: Exploring the Roles of Religious Beliefs and Ethnic Values. Clim Chang Program 2016;2(March):1-4.

16. Dattijo L, Nyango D, Osagie O. Awareness, perception and practice of female genital mutilation among expectant mothers in Jos University Teaching Hospital Jos, north-central Nigeria. Niger J Med 2010;19(3):311-5.

17. Amusan OA, Asekun-Olarinmoye EO. Knowledge, Beliefs, and Attitudes to Female Genital Mutilation (FGM) in Shao Community of Kwara State, Nigeria. Int Q Community Health Educ 2008;27(4):337-49.

18. Ahanonu EL, Victor O. Mothers' perceptions of female genital mutilation. Health Educ Res 2014;29(4):683-9.

19. Okeke T, Anyaehie U, Ezenyeaku C. An overview of female genital mutilation in Nigeria. Ann Med Health Sci Res 2012;2(1):70-3.

20. Epundu U, Ilika A, Ibeh C, Emelumadu O, Nnebue C. The Epidemiology of Female Genital Mutilation in Nigeria - A Twelve Year Review. Niger J Med 2018;6(1):1-10.

21. Saracoglu, M; Zengin, T; Ozturk, H; Genc M. Female Genital Mutilation/Cutting Type 4. J Androl Gynaecol 2014;2(4).

22. Imam. Yankan Gishiri (Salt Cut). Int J Obstet Trauma 2011;1(1):2-4.

23. WHO. A Systematic Review of the Health Complications of Female Genital Mutilation including Sequelae in Childbirth. 2000

24. Ndikom CM, Ogungbenro FA, Ojeleye OA. Perception and Practice of Female Genital Cutting among Mothers in Ibadan, Perception and Practice of Female Genital Cutting Among Mothers in Ibadan, Nigeria. 2017.

25. Sabahelzain M. FGM / C DECISION-MAKING PROCESS AND THE ROLE OF GENDER POWER. 2018;(November).

26. Rosenbaum TY, Abdo CHN, Byers ES. Ethical and Sociocultural Aspects of Sexual Function and Dysfunction in Both Sexes MVP Outcomes View project Healthy Sexuality and Adults with ASD. J Sex Med 2016;(13):591-606.

27. Alfano M, Arulampalam W, Kambhampati U. Female Autonomy and Education of the $\begin{array}{llll}\text { Subsequent } \quad \text { Generation: } & \text { Evidence } & & \end{array}$ http://conference.iza.org/conference_files/worldb2010/alfano_m6078.pdf. Accessed 6 November 2018.

28. Namdeo RP. Impact of Education on Decision-making Ability of Women. Educ Quest An Int J Educ Appl Soc Sci 2017;8:431-4.

29. Hugo F, Nesje B. Effects of Schooling on Female Genital Cutting The Case of Kenya. 2014 http://www.duo.uio.no/. Accessed 6 November 2018

Acknowledgements - Nil

Source of Funding - Nil

Conflict of Interest - Nil 